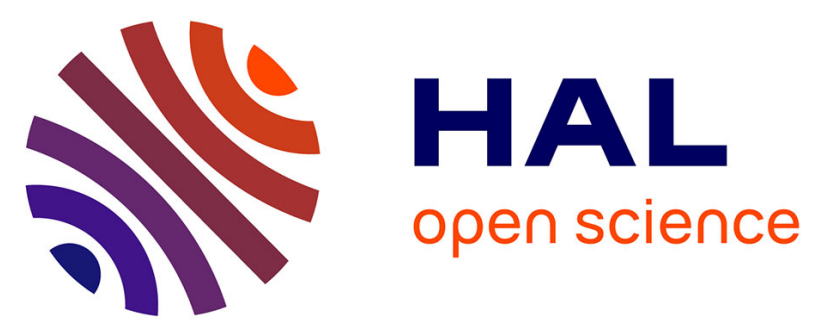

\title{
Helicene-grafted vinyl- and carbene-osmium complexes: an example of acid-base chiroptical switching
}

Emmanuel Anger, Monika Srebro, Nicolas Vanthuyne, Christian Roussel, Loïc Toupet, Jochen Autschbach, Régis Réau, Jeanne Crassous

\section{- To cite this version:}

Emmanuel Anger, Monika Srebro, Nicolas Vanthuyne, Christian Roussel, Loïc Toupet, et al.. Helicenegrafted vinyl- and carbene-osmium complexes: an example of acid-base chiroptical switching. Chemical Communications, 2014, 50 (22), pp.2854-2856. 10.1039/C3CC47825D . hal-01058225

HAL Id: hal-01058225

https://hal-univ-rennes1.archives-ouvertes.fr/hal-01058225

Submitted on 26 Aug 2014

HAL is a multi-disciplinary open access archive for the deposit and dissemination of scientific research documents, whether they are published or not. The documents may come from teaching and research institutions in France or abroad, or from public or private research centers.
L'archive ouverte pluridisciplinaire $\mathbf{H A L}$, est destinée au dépôt et à la diffusion de documents scientifiques de niveau recherche, publiés ou non, émanant des établissements d'enseignement et de recherche français ou étrangers, des laboratoires publics ou privés. 


\title{
Helicene-grafted vinyl- and carbene-osmium complexes: an example of acid-base chiroptical switching
}

\author{
Emmanuel Anger, ${ }^{a}$ Monika Srebro, ${ }^{b}$ Nicolas Vanthuyne,${ }^{c}$ Christian \\ Roussel, ${ }^{c}$ LoïcToupet, ${ }^{a}$ JochenAutschbach, ${ }^{*}{ }^{, d}$ RégisRéau, ${ }^{a}$ and JeanneCrassous, ${ }^{*}, a$
}

\begin{abstract}
The first helicene-based carbene osmium complex has been prepared from a vinyl-osmium derivative and this system has been shown to behave as a potential acid-base triggered chiroptical switch.
\end{abstract}

Helicene derivatives have recently shown potential as molecular materials due to their inherent chirality, large magnitude chiroptical properties and $\pi$-conjugated electronic structure. ${ }^{1}$ For example, they have revealed fascinating optical, redox or chemical-stimuli induced chiroptical switching. ${ }^{2,3}$ These compounds may find applications invarious domains such as in optical displays, telecommunications, or molecular electronics.The design of new types of functional chiral molecular switches is needed and in this context, the switching of chiral metal-based systems has great potential, ${ }^{2 \mathrm{c}}$ due to the possibility of reversibly modifying the molecule by changing the metal center's properties (geometry, redox state, ...). ${ }^{2 c, d}$ In this communication, we describe the synthesis of an unprecedented enantiopure carbeneosmium helicene complex from an enantiopure helicene-grafted vinylosmium derivative. The potential use of these chiral organometallic systems as acid-base chiroptical switches is examined. The electronic interaction between the vinyl-osmium or carbene-osmium units and thecarbo[6]helicenecore is investigated by DFT calculations.

Enantiopure vinyl-osmium-helicene complexes $\mathrm{M}$ - and $\mathrm{P}-2$ (Scheme 1) were prepared in good yield (65-70\%) using a known procedure, ${ }^{4}$ i.e. by hydro-osmylation of enantiopure $M$-(-)- and $P$-(+)-1 with 1 equivalent of $\mathrm{OsHCl}\left(\mathrm{P}^{i} \mathrm{Pr}_{3}\right)_{2}$ in $\mathrm{CH}_{2} \mathrm{Cl}_{2}$ at room temperature (r.t.). The NMR data fully support the proposed structure in accordance with previously reported analogues. ${ }^{4}$ For instance, the ${ }^{1} \mathrm{H}$ NMR spectrum of 2 displays the fingerprint for trans-ethylene metal-substituted moieties with a doublet of triplets at $4.80 \mathrm{ppm}\left({ }^{3} J_{\mathrm{H}-\mathrm{H}}=13.4 \mathrm{~Hz},{ }^{3} J_{\mathrm{P}-\mathrm{H}}=1.8 \mathrm{~Hz}\right)$ corresponding to the proton in the $\beta$ position of the osmium center.Furthermore, according to ${ }^{31} \mathrm{P}$ NMR spectroscopy the two $\mathrm{P}^{i} \mathrm{Pr}_{3}$ ligands are non-equivalent (23.96 and $23.92 \mathrm{ppm}$ ), indicating slightlydifferent chemical environments for the two fragments. The $\mathrm{X}$ ray structure of

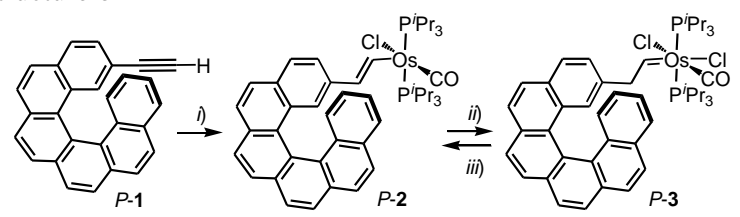

Scheme 1.Synthesis of enantiopurehelicene-grafted vinyl-osmium complex $P$-2 and osmium-carbene $P$-3fromenantiopure $P-1 . i) \mathrm{HOs}(\mathrm{CO}) \mathrm{Cl}\left(\mathrm{P}^{i} \mathrm{Pr}_{3}\right)_{2}, \mathrm{CH}_{2} \mathrm{Cl}_{2}$, r.t., $\mathrm{Ar}$, 3 days, $70 \%$.ii) $\mathrm{HCl}$, toluene, 10 min., $86 \%$.iii) $\mathrm{NEt}_{3}, \mathrm{CH}_{2} \mathrm{Cl}_{2}$.

complex 2 (Figure 1) reveals a square pyramidal pentacoordinated osmium center in which the two trans $\mathrm{P}^{i} \mathrm{Pr}_{3}$ ligands, $\mathrm{Cl}$ and $\mathrm{CO}$ form the basisofthe pyramidand the vinyl-helicene ligand is at the apical position. The Os-C1-C2-C3 bond lengths (1.987, 1.343 and $1.453 \AA$ ) are indicative of a trans vinyl-Os moiety that is almost coplanar with the helicene part $\left(\mathrm{Os}-\mathrm{C} 1-\mathrm{C} 2-\mathrm{C} 3,176.53^{\circ}\right)$, allowing an efficient $\pi$ interaction of the helicene ligand with theOscenter. The helical angle (angle between the terminal rings of the helix, 50.3 ) is similar to reported values for other metal-helicene compounds. ${ }^{3 \mathrm{a}}$ Overall, complex 2 is isostructural to its $\mathrm{Ru}$ analogue $\mathrm{e}^{3 \mathrm{a}, \mathrm{b}}$ but osmium complexes are usually less easy to handle due to a lower stability.

Complexes containing $\mathrm{Os}=\mathrm{C}(\mathrm{H}) \mathrm{R}$ units have been prepared. ${ }^{4 \mathrm{a}-\mathrm{e}} \mathrm{Such}$ carbene complexes (also named alkylidene-osmium complexes) are an important class of compounds but to our knowledge their electronic and chiroptical properties have not yet been studied.The first enantiopure helicene-based carbene-osmium complexes $M$ - and $P$-3 (Scheme 1) were straightforwardly prepared from vinyl-osmium complexes $M$ - and $P$-2 by a simple addition of slight excess of $\mathrm{HCl}$ in toluene at r.t. ${ }^{4 a}$ and characterized by ${ }^{1} \mathrm{H},{ }^{31} \mathrm{P}\left\{{ }^{1} \mathrm{H}\right\}$ and ${ }^{13} \mathrm{C}\left\{{ }^{1} \mathrm{H}\right\}$ NMR, along with IR, UV-vis and ECD spectroscopies. For example, the ${ }^{1} \mathrm{H}$ NMR spectrum of monocarbene 3 in $\mathrm{CD}_{2} \mathrm{Cl}_{2}$ showed the presence of a triplet at $18.1 \mathrm{ppm}\left({ }^{3} J_{\mathrm{HH}}=\right.$ $6.6 \mathrm{~Hz}$ ) which is typical of the $\mathrm{CH}=\mathrm{Os}$ and two doublets of doublets at 2.85 and $3.13 \mathrm{ppm}$ corresponding to the methylene group. In the ${ }^{13} \mathrm{C}\left\{{ }^{1} \mathrm{H}\right\}$ NMR spectrum, the $s p^{2}$ carbon appears as a doublet of doublet $\left({ }^{2} J_{\mathrm{CP}}=8,5 \mathrm{~Hz}\right)$ at $296.7 \mathrm{ppm}$. Furthermore, two singlets at 12.89 and $12.47 \mathrm{ppm}$ are found in the ${ }^{31} \mathrm{P}\left\{{ }^{1} \mathrm{H}\right\}$ NMR spectrum. These are typical values for aryl-methylene-carbene-osmium species ${ }^{4 \mathrm{a}}$ and correspond to the two $\mathrm{P}$ atoms in different chemical environments. Note that in such complexes the osmium centers are octahedral with a coordination sphere completed by a chloride ligand (see optimized structure in Figure 2). The Os-C1-C2-C3 dihedral angle in the calculated structure of 3 is $159.35^{\circ}$, which indicates a rotation of the helicene moiety around C1-C2 axis as compared to $\mathbf{2}$. See Supplementary Information, SI, for Cartesian coordinates of both calculated structures $\mathbf{2}$ and $\mathbf{3}$.

Vinyl-osmium helicene complex 2 displays two strong high-energy absorption bands (258 and $314 \mathrm{~nm}, \varepsilon \sim 70 \cdot 10^{3} \mathrm{M}^{-1} \mathrm{~cm}^{-1}$ and $45 \cdot 10^{3} \mathrm{M}^{-}$ ${ }^{1} \mathrm{~cm}^{-1}$, respectively, see SI) that originate from the $\pi$-system of the 


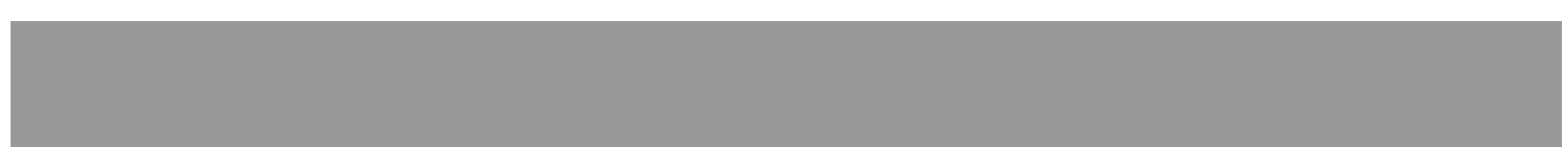

helicene ligand, along with abroadlow-energy band at $405 \mathrm{~nm}$ of moderate intensity $\left(\varepsilon \sim 14 \cdot 10^{3} \mathrm{M}^{-1} \mathrm{~cm}^{-1}\right)$ that does not exist in ligand $\mathbf{1}$ and is due to efficient electronic interaction between the vinyl-osmium moiety and the helicenic $\pi$-core (see below). Interestingly, the carbeneosmium complex $\mathbf{3}$ displays the same high-energy absorption bands as 2 for the $\pi-\pi^{*}$ transition of the helicene-core while the low-energy band at $405 \mathrm{~nm}$ has disappeared and two new broad bands of low intensity are found at $500 \mathrm{~nm}\left(\varepsilon \sim 5 \cdot 10^{3} \mathrm{M}^{-1} \mathrm{~cm}^{-1}\right)$ and $785 \mathrm{~nm}(\varepsilon \sim$ $3 \cdot 10^{3} \mathrm{M}^{-1} \mathrm{~cm}^{-1}$ ), see SI. In addition, enantiopure complexes $M$ - and $P$ 2display molar rotation (MR) values that are much higher than the correspondingligand $\mathbf{1}\left([\phi]_{D}^{3}\right.$ in ${ }^{\circ} \mathrm{cm}^{2} / \mathrm{dmol}: \quad P-\mathbf{2}: \quad+18000$ vs. $\quad P-\mathbf{1}$ : +11030). The circular dichroism (CD) spectrum of the complex $P-2$ depicted in Figure 1 shows, aside from the regular strong bands present in the helicene core, new ECD-active bands between $380-480 \mathrm{~nm}$ as compared with the ethynyl-substituted precursor $P$-1.These new bands involve electronic interaction between the vinyl-metal-center and the helical $\pi$-system as confirmed by density functional calculations performed at the BHLYP/SV(P) level (see SI for Computational Details). For example, calculated excitations $n^{\circ} 3(367 \mathrm{~nm})$ and $n^{\circ} 4$ (354nm)manifest character of $\pi$ to $\pi^{*}$ transitions within the helicene ligand (HOMO-LUMO: 65\% and HOMO-LUMO+1: 60\%, respectively; see Figure 2 and SI). Both excitations are at low energy / long wavelength, due to an enlargement of the helicene chromophore by conjugation through the vinyl bridge and osmium $d$ orbital involvement. Yet, because of the chirality of the helicene moiety, the transitions carry significant rotatory strength and contribute predominantly to the positive $\mathrm{CD}$ intensity at long wavelengths. In addition, a metal-centered excitation ( $\mathrm{n}^{\circ} 2,373 \mathrm{~nm}$, HOMO-4LUMO+2: 78\%) with moderate rotatory strength is present at lower energy. The resulting intense low-energy tail of the first positive ECD band is responsible for the increase in the molar rotation of the metalgrafted vinyl-helicene derivatives compared to the free ligands. Indeed, the calculated MR values of the $P$-isomers (2: 23915 with BHLYP and $17435{ }^{\circ} \mathrm{cm}^{2} / \mathrm{dmol}$ with LC-PBE0) reproduce well the strong increase relative to the helicene ligand (1: 17002 (BHLYP) and 13800 ${ }^{\circ} \mathrm{cm}^{2} / \mathrm{dmol}$ (LC-PBE0). See ref. 5 and SI for more details).

The osmium-carbene-helicene derivative revealed $[\phi]_{D}^{23}$ values close to those of the ligands $\left([\phi]_{D}^{23}\right.$ in ${ }^{\circ} \mathrm{cm}^{2} / \mathrm{dmol}: P-\mathbf{3}:+9600$ vs. $P-\mathbf{1}$ : +11030 ). The ECD spectrum of complex $P$-3shows a sharp negative band at $250 \mathrm{~nm}$ and a sharp positive one at $330 \mathrm{~nm}$ (Figure 1). Additionally, new weakly ECD-active bands at 500 and $785 \mathrm{~nm}(\Delta \varepsilon \sim$ 3-14 $\left.\mathrm{M}^{-1} \mathrm{~cm}^{-1}\right)$ are also present in $P-3$. TDDFT calculations on the singlet osmium carbene complexreproduced well the high-energy strong positive ECD-active bands in $\mathbf{P} \mathbf{- 3}$ originating from the purely helicenic $\pi-\pi *$ transitions (excitation $\mathrm{n}^{\circ} 5,309 \mathrm{~nm}, \mathrm{HOMO}-\mathrm{LUMO}+2$ : 50\% and HOMO-1-LUMO: 35\%, see Figure 2 and SI), calculated in the same energy range where the strongest rotatory strength excitation of it organic precursor 1 occurs. As depicted in Figure 2 and SI, for 3 these MOs are centered on the $\pi$-helical core without visible involvement of the osmium $d$ orbitals. Unlike complex 2 , it appears that in the carbene-osmium derivative $\mathbf{3}$ the electronic coupling between metal center and the helicoidal $\pi$-system is brokendue to the presence of the $\mathrm{CH}_{2}$.

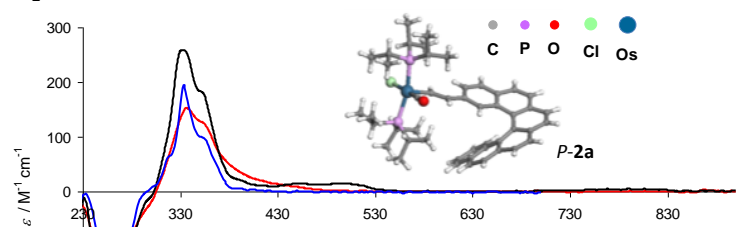

Figure1.CD spectra of $P-1$ a (blue) vs. $P$-2 (red) and $P$-3 (black) in $\mathrm{CH}_{2} \mathrm{Cl}_{2}$ (C 1-5 $10^{-5}$ $\mathrm{M}^{-1}$ ). Inserts: low-energy $\mathrm{CD}$ spectra of $P$-2,3.X-ray structure of complex 2 (one enantiomer shown).
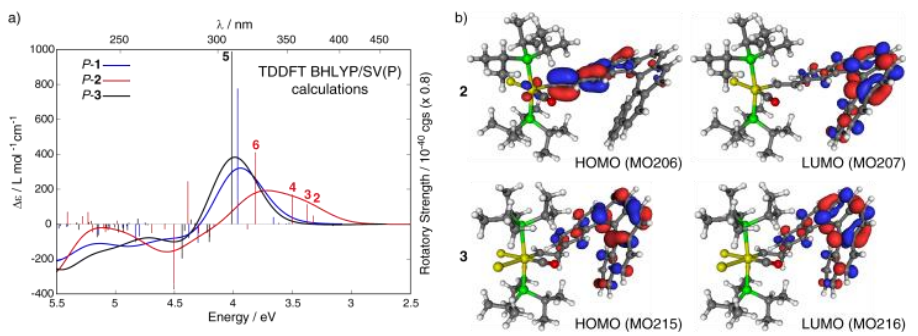

Figure 2. a) Calculated $C D$ spectra of $P$-1(blue), $P$-2(red), and $P$-3 (black)BHLYP/SV(P). b)Isosurfaces (0.04 au) of frontier MOs of $\mathbf{2}$ and $\mathbf{3}$.

Despite of the correct description of the high-energy part of the CD spectrum of $\mathbf{3}$, the very weak low-energy ECD-active bands could not be reproduced by a variety of non spin-orbit calculations. Absorptions to triplet excited states are often observed in heavy metal complexes because spin-orbit coupling weakens the spin selection rules. ${ }^{6}$ Calculations did indeed show the presence of triplet excitations in the wavelength range of interest. However, the appearance of triplet transitions above $600 \mathrm{~nm}$ was dependent on various approximations ${ }^{7}$ (see SI for more details). ${ }^{8}$ The calculated MR values of $\mathbf{3}$ were found to be overestimated as compared to the experimental result (17557 with BHLYP and 14173 with LC-PBE0) and similar to the calculated MR of 1. The trend among the set of complexes is thus correctly reproduced by the calculations. Another interesting question pertaining the electronic structure of $\mathbf{3}$ is the presence or absence of hyperconjugation $\left(\sigma-\pi\right.$ conjugation between $\mathrm{CH}_{2}$ and $\mathrm{C}=\mathrm{O}$ osor helicene)which may affect structure and bonding in metal carbene complexes $^{9}$ and leave signatures in UV-vis spectra. ${ }^{10}$ The optimized $\mathrm{BP} / \mathrm{SV}(\mathrm{P})$ geometry of $\mathbf{3}$ does however not exhibit structural features that usually would be identified with hyperconjugation. ${ }^{9,4 a}$

The ability of the helicene-osmium system to behave as an acidbase switch was examined. The reversible formation of helicene-vinylosmium $P$-2 from a solution of osmium-carbene-helicene $P-\mathbf{3}$ in $\mathrm{CH}_{2} \mathrm{Cl}_{2}$ was performed by simply using $\mathrm{NEt}_{3}$ and the UV-vis and $\mathrm{ECD}$ spectra of $P$-2were almost recovered (see SI). Furthermore, the IR spectra of complexes 2 showed a characteristic CO stretching mode ( $v_{\mathrm{CO}}$ ) at $1895 \mathrm{~cm}^{-1}$ that disappears upon adding $\mathrm{HCl}$ in toluene, while a new bandgrew up at $\sim 1932 \mathrm{~cm}^{-1}$ corresponding to 3 . This shows astronger donating character of the helicene-vinyl ligand compared to the carbene.The reverse transformation to $\mathbf{2}$ could be conducted by using $\mathrm{NEt}_{3}$ as followed by their IR $v_{\mathrm{CO}}$ (Figure 3). This transformation is thought to involve a deprotonation of the acidic $\mathrm{CH}_{2}$ group by the base 


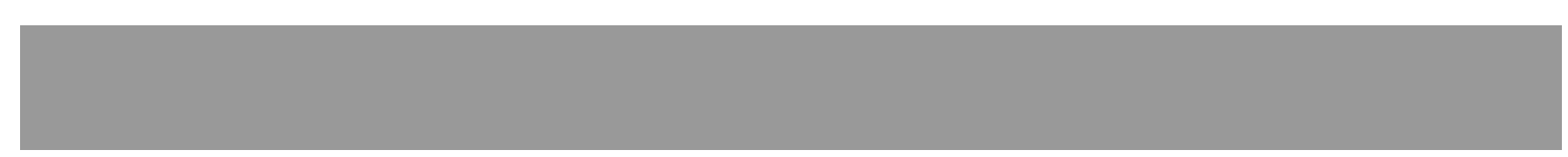

followed by a 1,3-shift leading to $\mathrm{HCl}$ abstraction. ${ }^{4 \mathrm{f}}$ As a consequence, this molecular system acts as an acid-base triggered chiroptical switch since the several ECD bands $(330 \mathrm{~nm}, 800 \mathrm{~nm}, \ldots)$ are greatly modified upon $2^{\leftrightarrow} \mathbf{3}$ transformation. Although the system is not practically efficient due to the low stability of highly diluted solutions of carbeneosmium derivatives, ${ }^{\#}$ to our knowledge this is the first time that a carbene derivative is used as a chiroptical switch.

In conclusion, the first enantiopure carbene-osmium based helicene derivative (3) has been prepared from unprecedented vinyl-osmium helicene derivative (2). The examination of the reversible transformation from $2 \leftrightarrow 3$ enabled to set up a new kind of an acid-base chiroptical switch due to the modification of the electronic interaction between the $\pi$-helical core and a grafted osmium moiety. This example illustrates the inspiration from simple and well-known organometallic chemistry to the design of new kinds of helicene-based molecular switching systems.

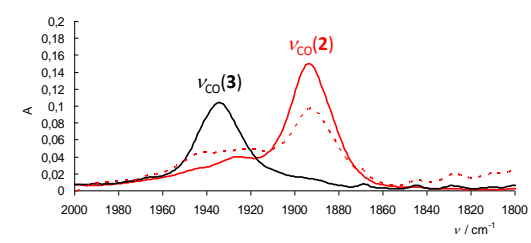

Figure 3. Reversibility test of the (carbene/vinyl)-osmium $\mathbf{2}^{\leftrightarrow} \mathbf{3}$ transformation.IR spectra in $\mathrm{CH}_{2} \mathrm{Cl}_{2}$ solution in the $1800-200 \mathrm{~cm}^{-1}$ region ( $v_{\mathrm{co}}$ stretching band). Spectrum obtained after $\mathbf{3} \rightarrow \mathbf{2}$ transformation is indicated in dashed red lines.

\section{Notes and references}

${ }^{a}$ InstitutdesSciences Chimiques de Rennes, UMR 6226, Institut de Physique de Rennes, UMR 6251, CNRS - Université de Rennes 1, Campus de Beaulieu, 35042 Rennes Cedex, France. Fax: (+33) 2-23-23-69-39; Tel: (+33) 2-2323-57-09; E-mail: jeanne.crassous@univ-rennes1.fr ${ }^{b}$ Faculty of Chemistry, Jagiellonian University, 30-060 Krakow, Poland. ${ }^{c}$ Chirosciences, UMR 7313, StéréochimieDynamique et Chiralité, Aix-Marseille University, 13397 Marseille Cedex 20, France. ${ }^{d}$ Department of Chemistry, University at Buffalo, State University of New York, Buffalo, NY 14260, USA. E-mail: jochena@buffalo.edu

Acknowledgements: The authorsthank the Ministère de la Recherche et de l'Enseignement Supérieur, the CNRS, the Région Bretagne, Rennes Métropole, and the ANR (12-BS07-0004-METALHEL-01). The theoretical work has been supported by grants CHE 0952253 and1265833from the National Science Foundation (JA) and the Foundation for Polish ScienceHoming Plus programme co-financed by the European Regional Development Fund under the Operational ProgrammeInnovativeEconomy(MS).The Center for Computational Research (CCR, Buffalo)has provided computational resources.

$\dagger$ Electronic Supplementary Information (ESI) available: experimental procedures, X-ray data and theoretical calculations. See DOI: $10.1039 / \mathrm{b} 000000 \mathrm{x} /$

\#Complex $\mathbf{3}$ is stable for several months if kept under rigorously inert atmosphere. However, it was not practically feasible to perform several reversible cycles due to successive adding of reagents in the solution and therefore changes in concentrations.

1 Y. Shen, C. -F. Chen, Chem. Rev., 2012, 112, 1463.
2 (a) B. L. Feringa, W.R. Browne, MolecularSwitches, Wiley-VCH, 2001; (b) D. Amabilino, Chirality at the Nanoscale, Nanoparticles, Surfaces, Materials and more, Wiley-VCH, 2009; (c) J. W. Canary, S. Mortezaei, J. Liang, Coord. Chem. Rev., 2010, 254, 2249; (d) H. Miyake, H. Tsukube, Chem. Soc. Rev., 2012, 41, 6977.

3 Helicene based chiroptical switches: (a) E. Anger, M. Srebro, N. Vanthuyne, L. Toupet, S. Rigaut, C. Roussel, J. Autschbach, J. Crassous, R. Réau, J. Am. Chem. Soc., 2012, 134, 15628; (b) J. Nishida, T. Suzuki, M. Ohkita, T. Tsuji, Angew. Chem. Int. Ed., 2001, 40, 3251; (c) T. J. Wigglesworth, D. Sud, T. B. Norsten, V. S. Lekhi, N. R. Branda, J. Am. Chem. Soc., 2005, 127, 7272; (d) Z. Y. Wang, E. K. Todd, X. S. Meng, J. P. Gao, J. Am. Chem. Soc., 2005, 127, 11552; (e) T. Biet, A. Fihey, T. Cauchy, N. Vanthuyne, C. Roussel, J. Crassous, N. Avarvari, Chem. Eur. J., 2013, 19, 13160; (f) H. Maeda, Y. Bando, K. Shimomura, I. Yamada, M. Naito, K. Nobusawa, H.Tsumatori, T. Kawai, J. Am. Chem. Soc., 2011, 133, 9266.

4 (a) M. A. Esteruelas, F. J. Lahoz, E. Onate, L. A. Oro, C. Valero, B. Zeier, J. Am. Chem. Soc., 1995, 117, 7935; (b) H. Werner, M. A. Esteruelas, H. Otto, Organometallics, 1986, 5, 2295; (c) M. A. Esteruelas, A. M. Lopez, M. Olivan, Coord. Chem. Rev., 2007, 251, 795; (d) M. A. Esteruelas, F. J. Lahoz, A. M. Lopez, E. Onate, L. A. Oro, Organometallics, 1994, 13, 1669; (e) M. A. Esteruelas, A. M. Lopez, Enrique Onate, Organometallics, 2007, 26, 3260; (f) S. Jung, C. D. Brandt, J. Wolf, H. Werner, Dalton Trans., 2004, 375.

5 (a) M. Srebro, N. Govind, W. A. de Jong, J. Autschbach, J. Phys. Chem. A, 2011, 115, 10930; (b) M. Srebro, J. Autschbach, J. Chem. Theory Comput., 2012, 8, 245; (c) M. El Sayed Moussa, M. Srebro, E. Anger, N. Vanthuyne, C. Roussel, C. Lescop, J. Autschbach, J. Crassous, Chirality, 2013, 25, 455.

6 Selected examples of Os complexes with triplet state absorption: (a) C. -C. Hsu, C. -C. Lin, P. -T. Chou, C. -H. Lai, C. -W. Hsu, C. -W. Lin, Y. Chi, J. Am. Chem. Soc., 2012, 134, 7715; (b) B. Le Guennic, W. Hieringer, A. Gorling, J. Autschbach, J. Phys. Chem. A, 2005, 109, 4836; 7 (a) M. J. G. Peach, M. J. Williamson, D. J. Tozer, J. Chem. Theory Comput., 2011, 7, 3578; (b) M. J. G. Peach, D. J. Tozer, J. Chem. Phys. A 2012, 116, 9783; (c) M. J. G. Peach, N. Warner, D. J. Tozer, Mol. Phys. 2013, 111, 1271; (d) B. Moore, II, J. Autschbach, J. Chem. Theory Comput. 2013, DOI: 10.1021/ct400649r; (e) M. Rudolph, T. Ziegler, J. Autschbach, Chem. Phys. 2011, 391, 92.

8 Absorptions at wavelengths above $600 \mathrm{~nm}$ have been reported for Os(III)-based complexes, which were assigned to doublet-doublet and doublet-quartet metal-to-ligand charge transfer transitions.See: K. D. Demadis, D. M. Dattelbaum, E. M. Kober, J. J. Concepcion, J. J. Paul, T. J. Meyer, P. S. White, Inorg. Chim. Acta, 2007, 360, 1143.

9 M. M. Francl, W. J. Pietro, R. F. Hout, Jr., W. J. Hehre, Organometallics, 1983, 2, 281.

10 (a) C. L. Daisy, Chem. Rev., 1945, 36, 145; (b) R. S. Mulliken, J. Chem. Phys., 1939, 7, 339; (c) C. F. Bernasconi, A. E. Leyes, J. Am. Chem. Soc., 1997, 119, 5169; (d) P. Hamon, F. Justaud, O. Cador, P. Hapiot, S. Rigaut, L. Toupet, L. Ouahab, H. Stueger, J. -R. Hamon, C. Lapinte, J. Am. Chem. Soc., 2008, 130, 17372. 